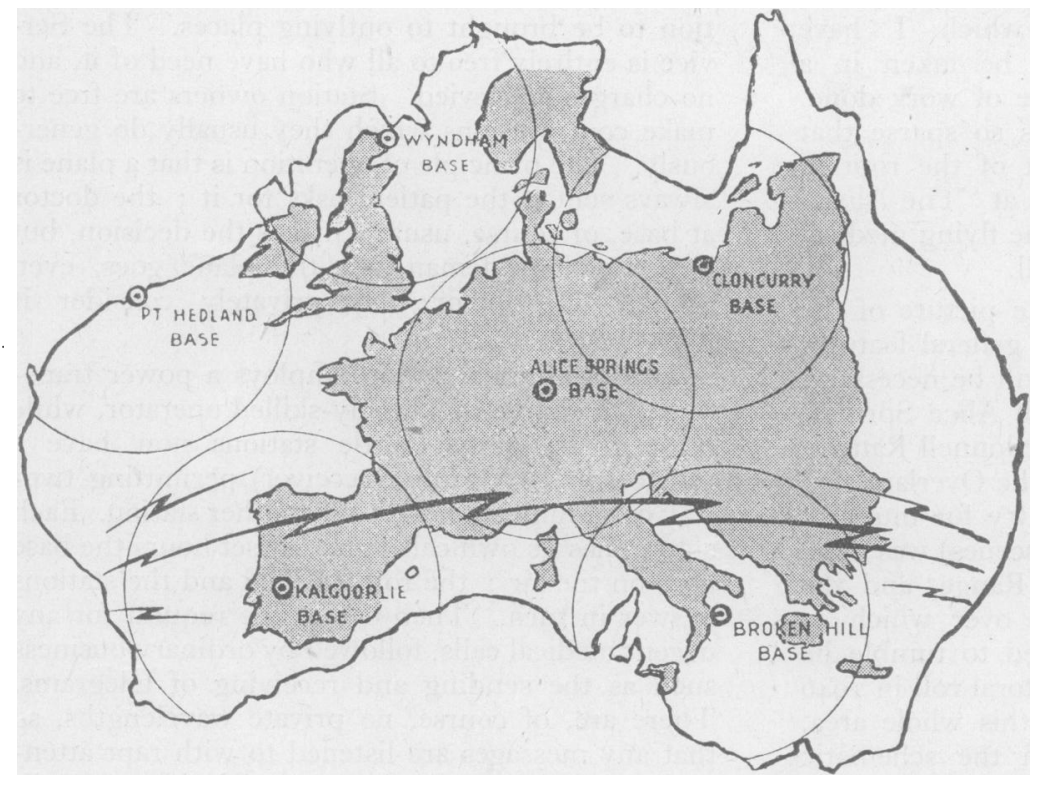

Fig. 1.-An idea of distances. Europe and Australia superimposed, on the same scale.

\title{
THE FLYING DOCTOR SERVICE OF
}

By L. C. LuM, M.R.C.P., M.R.A.C.P.

Australia was the first country to organize medical service for sparsely settled areas by means of wireless communication and aerial transport. Although it was in 1917 that the Board of the Australian Inland Mission commenced advocating the need of wireless facilities and flying doctors, it was not until May 17,1928 , that the numerous technical difficulties were overcome and the inaugural flight was made. The service was operated on an experimental basis from Cloncurry, in Queensland, and after a trial period of a year it was decided to continue and expand it. By 1939 it had grown to its present size, despite financial difficulties in the depression years. It should be noted at the start that this service was conceived, developed and financed entirely by private individuals.

Nowadays, despite the fact that romantic propaganda has made the Flying Doctor Service of Australia well known by name, its working is largely unknown, even to Australians, for they are for the most part unacquainted with life in the vast outback of their sub-continent; and the popular imagination, having visualized a dostor standing by with a plane ready to fly anywhere at the drop of a hat, stops short at this point. This is far from the story. Most of our eight million people are concentrated in the coastal belt particularly to the east ; the capital cities Brisbane, Sydney, Melbourne and Adelaide being 500 to 600 miles apart, while Perth, on the southwestern corner is r,400 miles from Adelaide, and the trans-continental railway, in running across the Nullarbor Plain, enjoys the dubious distinction of having the longest straight stretch of line in the world, 300 miles without a bend or curve. Inland lies ' the bush,' vast, arid, though rarely desert. Here if your nearest neighbour is within 30 miles you count yourself lucky. Often the nearest is 100 miles or more away, and individual cattle holdings reach fantastic sizes. Victoria River Downs Station, for example, covers an area of 15,000 square miles-one of the largest cattle runs in the world. This is part of the country covered by the Flying Doctor Service. It is served by the 'pedal wireless'-the remarkable system of pedal operated radio transmitters developed specifically for this work.

There are now seven flying doctor bases (see map) each being equipped with a powerful transmitting station and having available a doctor and aerial transport to provide medical service to the 
remotest corners of the continent. Each base serves the area within a radius of approximately 500 miles. This article deals with the Alice Springs area, the one with which I have been associated, and which can be taken in a general way as typical of the type of work done. Here, however, the population is so sparse that the flying service forms but part of the routine duties of the two resident doctors at 'The Alice.' In other centres there is a full-time flying medical officer and plane constantly on call.

In order to present an accurate picture of the Service a short digression on the general features of the Central Australian scene will be necessary. In the centre lies the township of Alice Springs, in a picturesque valley in the Macdonnell Ranges. Those who have seen the film ' The Overlanders,' will have some idea of this country for much of the filming (except tropical river scenes) was done on the tablelands north of the Range, and the imposing rock faces and gorges over which so many unfortunate beasts appeared to tumble lie just south of the town. The electoral roll in 1946 showed some 1,200 persons for this whole area, whose size can be judged from the schematic superposition of a map of England. It is linked by railway with Adelaide, I,000 miles to the south, with virtually no townships of significant size for 800 miles. A single bitumen road leads to Darwin, r,000 miles to the north. The nearest township is Tennant Creek, a flourishing goldmining centre 300 miles north. This is, in the main, cattle country, dry and desolate, the cattle watering at bores for there is a plentiful supply of sub-artesian water. 'To the south-east of 'The Alice' lies the Simpson Desert, 30,000 square miles of shifting sand dunes, and one of the last unexplored places of the earth. It was crossed for the first time in 1938. Elsewhere are a few tiny mining settlements, mostly mica and wolfram, while 300 miles to the north-west over a waterless plain, are The Granites, a massive outcrop of black rock, scene of an abortive gold rush in the r93os.

The medical service throughout the Northern Territory is part of the Commonwealth Department of Health. All medical and dental service is entirely free, and doctors, dentists and nurses are salaried officers of the Department. Alice Springs is the Central Australian base with a wellequipped hospital taking up to 40 beds, two medical officers, a dental officer and nursing and ancillary staff. The Flying Doctor Service is a separate entity which, however, works in the closest co-operation with the Department. It is a private organization financed entirely by voluntary contributions throughout Australia, with a Section in each capital city which is responsible for the upkeep of the centres under its control. The
Alice Springs centre, for example, is run by the South Australian Section. It supplies the planes and wireless facilities which allow medical atten $\mathbb{\mathscr { Q }}$ tion to be brought to outlying places. The Ser vice is entirely free to all who have need of it, and no charges are levied. Station owners are free to $\mathscr{\sigma}^{\circ}$ make contributions which they usually do genere ously. The principle of operation is that a plane is always sent if the patient asks for it; the docto? at base, of course, usually makes the decision, but if the patient demands it the plane goes, evers though the doctor may privately consider it unnecessary.

The base radio station employs a power trans $\vec{\omega}$ mitter in charge of a highly-skilled operator, whiles most of the larger cattle stations now have transceiver (transmitter-receiver) permitting two way communication with the mother station. Eachon station has its own call sign. At set hours the baseु goes on the air ; the roll is called and the stations answer in turn. Then comes the request for any urgent medical calls, followed by ordinary business such as the sending and receiving of telegrams. There are, of course, no private wavelengths, sothat any messages are listened to with rapt atten tion by all the other stations, and intimate details of so-and-so's trouble with his waterworks are instantly spread over an area as big as Westepno Europe. Individual stations may afterwards arrange a private schedule with each other fos little gossip. The doctor does not attend theses sessions unless especially asked for or unless he wants to question the patient himself. The्य answer to many minor queries can be relayed byD phone through the radio operator. The usuaf problems of general practice crop up ; the or-윽 dinary minor complaints, accidents, fractures from horseback spills, and the 'occasional case of surgical or medical emergency. The 'abdominal. pains' provide problems that can readily be imagined ; obviously, if the service is to function efficiently the decision to send out a plane on a long and costly flight cannot be taken lightly.

More often than not there is no necessity for the doctor himself to fly out, and in such a sparselyo populated area as this it is obvious that under normal conditions he need not undertake a greato number of trips. The position is different in otherareas where the full-time flying doctors habituallyo fly thousands of miles per month, but here it oftenn suffices to send the plane out to fetch the patient, or even to advise the latter to come in on the nexto mail run. However, the knowledge that one may at any time be required to do a flight of up to 500 miles over an arid and inhospitable land adds as certain zest to every routine session on the air One does not always fly on these occasions ; theremay be no airstrip handy to one's destination, $\mathbb{\mathbb { D }}$ 


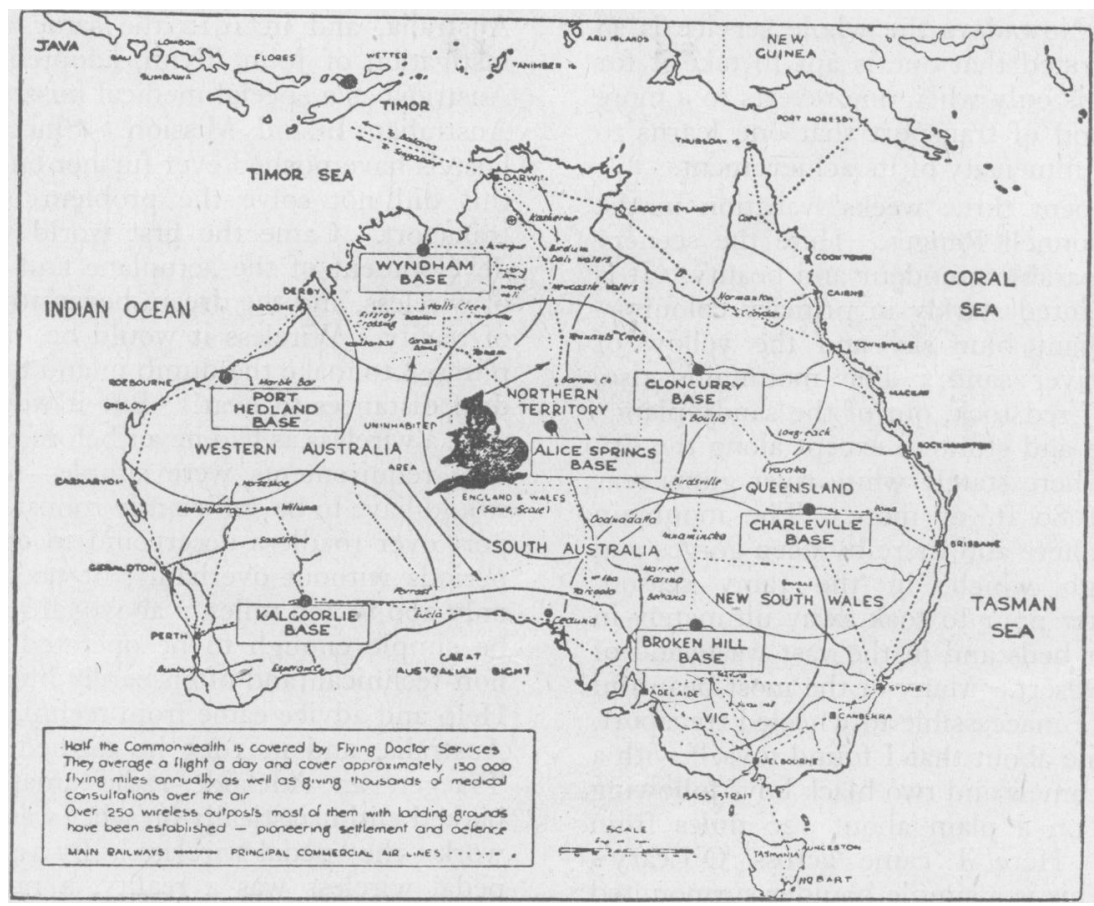

Fig. 2.-Radii of action of the Flying Doctor Services.

when it will be more convenient to go by utility car. Such trips are far more exciting, though more lengthy for there are no made roads and the terrain is infinitely varied, from creeks where to get bogged in the sandy bed may mean half a day's digging to get yourself out, to flat earth plains good for a comfortable 50 m.p.h., or rocky gorges along which three miles per hour is good going. Distance and isolation must here be measured in time, not miles. You take the $t$ ansport which will get you there most quickly. Often it is necessary to do a long journey by truck from the airstrip to the patient.

The planes are chartered from a private airline company which pioneered the air service within the Northern Territory in the r93os, and developed the system of small landing strips which the planes use at key stations throughout the Territory. They fly a regular mail circuit, and on these runs the pilots may pick up any sick person they think needs medical attention. They show very good judgment in selecting cases ; for example they are well aware of the hazards of flight to patients with pneumonia and will never on their own initiative transport a patient whom they suspect of suffering from it. In addition to the regular airstrips many outlying stations have an emergency landing ground. These are just a flat piece of ground from which all trees, bushes and large stones have been cleared sufficient too serve a light plane. Their serviceability is menaced by three things : firstly termites which are forever building 'ant-heaps' (which are amazingly solid); secondly small trees and bushes ; thirdly, the chronic reluctance of their owners to keep the runway clear and to unfurl the windsock, which is apt to be wrapped around the post when you arrive. Landing under these conditions involves a preliminary low level inspection, the pilot estimating wind direction by the behaviour of the plane. Then you come in on a wing and a prayer. One such station owner excused his negligence-we had just put down amongst a pretty collection of ant-heaps and tree stumps-nn the grounds that he didn't want the Japs to be able to use his aerodrome if they invaded us (this was in 1943)!

Although the plane gets much of the glamour, the perhaps greater importance of the radio network must be emphasized, for the latter is, in truth, the very nerve centre without which the organization could hardly work at all. To the people of the outback it is their window on the outside world and an invisible back fence over which neighbourly gossip can be bandied for hundreds of miles. The Flying Doctor Service of Australia could not be inaugurated until a special two-way radio had been developed specifically for 
this purpose. Nowadays the whole service is so smoothly integrated that one is apt to take it for granted, and it is only when one reverts to a more primitive method of transport that one learns to appreciate the immensity of its achievement.

In 1947 I spent three weeks' vacation in the Western Macdonnell Ranges. Here the scenery is of an incomparable grandeur and beauty. It is a landscape painted starkly in primary coloursred rock, brilliant blue sky and the yellow of spinifex and river sand. The mountains rise, sheer masses of red rock, out of the sandy plain ; trees are scarce and stunted, except along the dry watercourses where stately white river gums rear to a height of $80 \mathrm{ft}$. or more. The mountain ridges are cleft here and there by deep gorges and chasms through which, in the rainy season, torrents of water pour to soak away ulfimately in the sandy river beds and in the vast wasteland of the Simpson Desert. Many of the most beautiful places are quite inaccessible to wheeled transport, and thus it came about that I found myself with a team of three camels and two black boys following a cattle track on a plain about 120 miles from 'The Alice.' Here I came across O'Leary's tombstone. This is a simple boulder surmounted by a rough hewn cross, and crudely inscribed

\section{In Memory of}

P. J. O'Leary,

Who died on Nov. I0, 1926. Aged 33 yrs.

Cut by $\mathrm{H}$. Beland.

O'Leary (I later discovered) was a cattle man who suffered from stricture. One day acute retention supervened. He sent a couple of black boys to the Hermannsburg Mission Station some 40 miles away to bring the missioner and some catheters, but it chanced that the missioner himself was at that time quite incapacitated from sandy blight and could hardly see. After a few days he recovered enought to make the trip, but it was too late. Unable to endure the agony any longer, O'Leary had opened his bladder with a penknife through a suprapubic incision, and was moribund from peritonitis.

Such lonely graves are scattered in wild places throughout the Australian outback, and many other pioneers have perished without a stone to commemorate their death ; women in childbirth, drovers from accident and disease. Such tragedies -only too common-inspired a Presbyterian minister of the outback, the Rev. John Flynn, to dream of an aerial medical service. Since 1907 the Presbyterian Church in Australia had been sending out nurses into the far places of the Australian bush. In I9I I the first bush nursing hostel was established at Oodnadatta in South
Australia, and in 1912 the same church, at tho instigation of John Flynn, adopted two-thirds of Australia as a special medical missionary area, th Australian Inland Mission. Since then nursing hostels have pushed ever further outback. But al this did not solve the problem of doctors and transport. Came the first world war, the rapig development of the aeroplane and the early days of wireless, and the dream began to take the shap of reality. Wireless it would be, in Flynn's own phrase 'to make the dumb inland to speak, and its deaf distances to hear.' But it would have to be such a wireless as had never before been conceived. The requirements were simple-too simple. It would have to be sufficiently robust to stand trans? port over roadless desert and to operate for long periods without overhaul; it needed a range of only 200 te 300 miles; above all it would have tof be simple enough to be operated by completeliso non-technical (and often barely literate) bushmen. Help and advice came from technical men all over Australia, and in 1925 he teamed with Mr. Alf Traeger, an Adelaide radio amateur, who em? barked enthusiastically on what was to be his life's work - the 'pedal wireless.' By 1928 the Traegeग̃ pedal wireless was a reality, a radio transmitten and receiver whose generator was driven by bicycle pedals. It was at first the fruit of yearso unremitting toil, experiment and frustration. 영 would not permit voice transmission, and operator, when possible the station manager's wife had to learn Morse Code. The first installatio was presided over by Mr. Traeger and the ladio prepared to transmit her first message. Stage fright set in, 'Oh dear, what shall I say ?' 'Any? thing, say hallo Maurie' (the latter was the base operator). The message was received in faltering Morse 'Hell ! O Hell ! O Maurie ' silence.

Later came another invention, the dictagraph essentially a Morse typewriter ; you pressed the appropriate key and the Morse letter went out ow. the ether. Soon the pedal wireless from being medium for 'S.O.S.' only became a channel foy gossip, and drew the comment from a lubra anent her mistress's radiotelephonic activities? 'That fella bike no good. Missus bin ride 'im a day, too much talk-talk come up nowhere.' Other improvements followed and the dictagraph gavos place to a microphone. The classic of this period was "This is XY calling. I have a message for Doctor ... Pedal harder you black bastard !' $\omega$

Now the latest sets are equipped with an or dinary telephone handset; on lifting the instrue ment a bell is rung in the base station and opera $a_{\infty}^{\mathbb{D}}$ tion is somewhat simpler than a telephone in that there is no need to dial.

Stations have a standard medical chest $\operatorname{con} \stackrel{\circ}{\circ}$ 
taining a few instruments and a supply of drugs, each having its own code number and its own place in the chest. One prescribes drugs both by name and by number. The progress of the patient can be followed closely at the routine sessions, and reports are usually fairly reliable. The people of the bush, from sheer necessity, have learned what constitutes relevant medical information. A few calls prove to be furphies due to panic or sheer lack of consideration, but this is far rarer than in urban practice, and the Service is quite willing to do any number of unnecessary flights in order not to miss a really urgent one ; and there is always the other side of the story. One call came rather apologetically from an old-timer to deal with what was described as ' a small cut on the base of the thumb' which would not stop bleeding. This did not seem much for a special flight but it turned out to be a large gash extending on to the wrist which had cut the radial artery!

The aborigines are a source of much interest, medical and otherwise. The central area has no exotic tropical diseases apart from yaws, which is endemic and epidemic among the natives. A very occasional case of leprosy crops up ; it is more common at the 'top end' (Darwin area). Trachoma is perhaps the greatest scourge of the native and periodically outbreaks of the acute condition sweep through camps and mission stations. At such times the whole natural history of the disease unfolds as one examines case after case ; the young children with a very acute conjunctivitis, photophobic, the palpebral fissure ringed with flies devouring the discharges ; young adults with developing tarsal plate scarring and corneal nebulae ; older adults with ulceration and gross corneal opacities, entropion and trichosis; and finally the aged blind. The latter make a pitiable spectacle, squa ting forlornly round the camp fire with advanced painful entropion and constant purulent discharge from the eyes. The universal incidence of the disease is accounted for by the flies which everywhere in the bush teem in uncountable millions. They are incredibly، persistent, and can scarcely be brushed away. The natives make no attempt to do so, consequently they almost invariably carry a row of flies sitting on their lower eyelids and feeding at the lid margin. The epidemics can be cut short magically by the wholesale administration of a short course of sulphonamide to the whole camp.

Yaws also travels in epidemic waves across the country. My first introduction to such an epidemic came when an outlying station reported that a group of natives on walkabout who had passed nearby were suffering from the disease. I determined to put the diagnosis to serological proof, and having arrived in the area, guided by a black tracker, we eventually discovered the camp some ten miles from the station on a sparsely wooded flat adjacent to a dry watercourse. So unobtrusively do these people melt into the landscape (when it suits them) that our car was in the midst of their camp before I saw them. There were perhaps 30 natives including about 12 children. Most of the latter, together with some of the younger women, had eruptions of varying severity from a few dirty encrusted sores on the limbs to a severe generalized eruption of similar lesions over the whole of the body and limbs. The latter case was a young girl, and since the lesions were all oozing pus or bleeding and each lesion was supplied with its quota of flies, her plight was most pitiable. Having overcome the difficulties incidental to lighting a primus stove in the face of a strong, gusty wind and to persuading a group of myalls to undergo venepuncture, I collected half a dozen samples of blood and gave those who submitted to the procedure a shot of N.A.B. for their trouble. All specimens gave a strongly positive W.R. The generalized eruptions respond with amazing speed to N.A.B. and these healed within a few days. It is probable that the majority of the natives in the area have been infected at some time with yaws, although ' boomerang tibia,' usually attributed to this causes is not commonly seen.

Measles epidemics occasionally occur and carry? a high mortality, the incidence of lung complications being considerable. They present at first. a problem in diagnosis, since the dark skin obscures most of the characteristics of the rash. Fortunately Koplik spots will usually provide the answer. In one small outbreak which I saw in 1943 the death rate was 25 per cent., and other outbreaks in the last two years have carried a similar high mortality. It is interesting to note the nursing methods employed by aborigines in time of sickness. The sufferer lies on the ground half nursed in the arms of a friend or relative, and if he happens to be one of the older men and therefore a person of some importance, others compete for this honour. Once in visiting a camp of completely uncivilized blacks, I examined an old man, obviously a person of consequence, semirecumbent in the lap of one man and surrounded by a crowd of other bucks all squatting as close to the patient as possible and trying to get hold of some part of his anatomy in order to share in the honour of nursing. On the outskirts of the crowd hovered a very unhappy young man who was under suspicion of pointing the bone at the patient. The latter was suffering severely from sciatic pain, and my explanation that this could not be due to black magic did not go very far towards exculpating the youth. Fractures of the leg get similar treatment, 


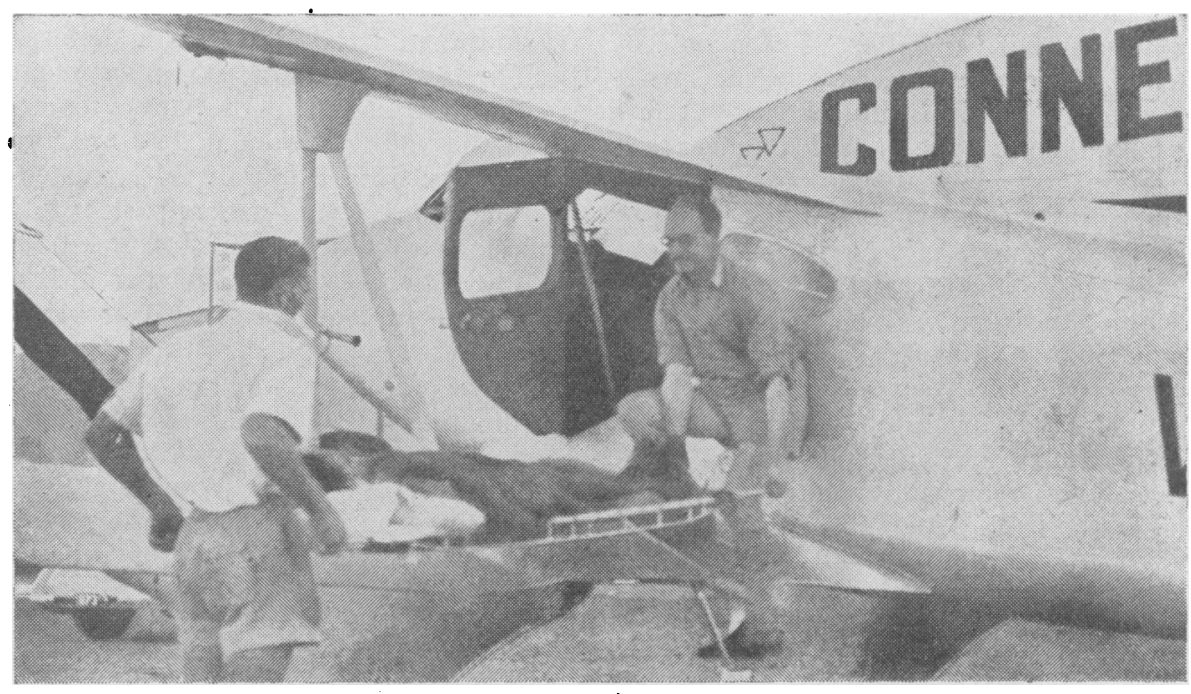

FIG. 3.-Careful handling is most important.

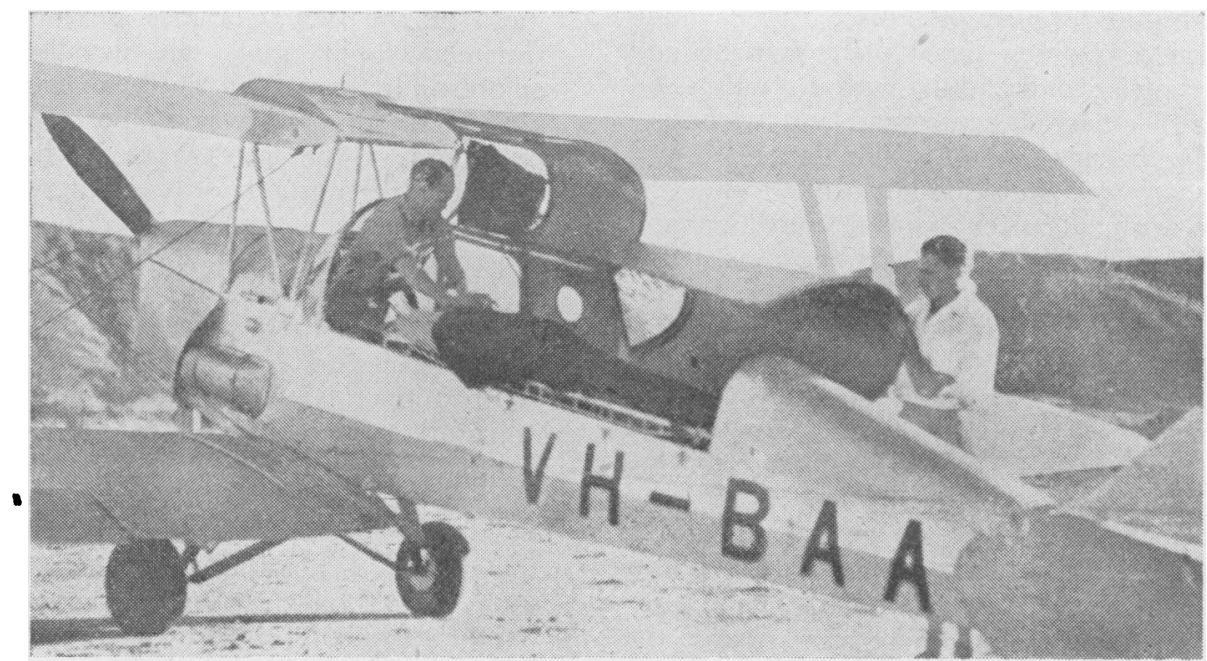

Fig. 4.-The patient comfortably settled in the ambulance plane. 
and a youth with a fractured femur whom I picked up in the bush about six weeks after the accident had commenced union in reasonable position and no more than $\mathrm{I}$ in. shortening. When first seen he was half lying on the ground with a friend supporting the body and another sitting at the feet holding the leg straight and preventing rotation of the foot. This vigil had been going on in continuous relays since the injury. With treatment in hospital he obtained quite good functional recovery. If left to themselves, however, they tend to commence weight bearing before union is solid and so develop remarkable deformities.

Detribalized natives who live on the fringe of the white settlements subsist chiefly on the rations provided for them by the Department of Native Affairs, for any considerable number of blacks encamped in one area soon deplete it of native vegetable fcods, and kangaroos and other fauna soon disappear. Consequently the ration of meat, flour, sugar, tea and jam, with a total calorific value of aisout 1,800 (mainly carbohydrate) constitutes their whole diet ; and yet, in a survey of some 400 blacks in this area in 1943, I could detect no real clinical evidence of vitamin deficiencies. In drought seasons, however, epidemics of scurvy have occurred under such conditions, though I have had no personal experience of this. In this parched land, with little surface water, aboriginal food is scarce, most productive land having been taken over for agriculture, and the natives thus excluded from their traditional hunting grounds. Consequently the myalls, in their native state, have to be constantly on the move in order to get food. These myalls, even in the most remote areas, are almost always friendly, though they may avoid the white man through timidity. In the history of this continent any attacks by natives on whites have almost invariably been caused by treachery on the part of the latter, particularly in regard to native women. Yet they have maintained their friendly attitude in the face of the most appalling and inhuman treatment, and many a bushman owes his life to succour given by wild natives when he was lost in the bush. Poisoning of water holes, the distribution of flour containing strychnine and wholesale shootings are crimes which have gone on, not only in the distant past but within the last 20 years. I have met a cattle man who boasted of punishment of his blacks by chaining them on the tin roof of a shed - this in a tropical region where, at that time, the indoor temperature remained at $110^{\circ}$ at midday for over a month ; and another who killed a native by tying him with a lasso to the back of his truck and driving on. Such blots on our record must be balanced against the rigours of the country and the toughness of fibre required of pioneers in wresting a living from it. Among white people acts and lives of quiet heroism are accepted as part of the ordinary run of life. A drover's wife had suffered from severe asthma for over 20 years, yet had spent those years with her husband, living in droving camps under most primitive conditions and rearing a family of five. I saw her at Newcastle Waters in 1943 and was able to terminate a severe attack with adrenaline-the first time she had ever received the drug. In one long flight (a round trip of 1,000 miles to bring in a native with a fractured skull) we touched down for refuelling at an isolated gold mine where there was an emergency landing strip. The mine was at that time being worked by a young white woman with the aid of anumber of blacks. Her husband was then serving in the Army, and she, the only white person on the place, was carrying on with the job, 300 miles from the nearest town and 100 miles from her nearest neighbour, in the midst of some of the most arid and inhospitable land in the Northern Territory. These things I find more? eloquent of the land and its people than the isolated deed of courage and endurance in times of unusual stress, though it is the latter which receives publicity.

The doctor's life in these parts is very full and varied. He must be prepared to handle any emergency, medical or surgical, to be his own $\mathrm{X}$-ray technician, to do pathological investigations and at times his own dispensing. But above all there is the fascination of the outback and its people, and the unique beauty of its landscape. The Northern Territory of Australia exercises a spell over the minds of whoever have been associated with it and draws them back.

A good idea of the Flying Doctor Service, as well as an excellent yarn, will be found in the following books which are recommended to any interested reader: 'Flynn of the Inland' by Ion Idriess, ' Flying Doctor Calling' by Ernestine Hill, and 'Flying Doctor' by Clyde Fenton. 